\title{
Religión, "sectas" y control social en la China de Xi Jinping
}

\section{Religion, "sects" and social control in Xi Jinping's China}

\author{
MASSIMO INTROVIGNE \\ Centro de Estudios sobre Nuevas Religiones (CESNUR), \\ Turin, Italia \\ maxintrovigne@gmail.com
}

Resumen: Las reformas legales y administrativas de Xi Jinping en el ámbito de la religión han tenido un gran impacto. Los tres segmentos de la religión sufrieron el "mercado rojo" que incluye las cinco religiones controladas por el Estado; el "mercado negro" de los grupos prohibidos (xie jiao); y el "mercado gris" de las iglesias, templos y mezquitas técnicamente ilegales, pero a veces toleradas. Durante la administración de Xi se tomaron continuamente medidas para eliminar el "mercado gris", bien convenciendo a las congregaciones para que se unieran al "mercado rojo" oficial, bien destruyendo los lugares de culto y deteniendo a los líderes locales. Las congregaciones católicas disidentes también fueron eliminadas mediante una combinación de represión policial y acuerdos diplomáticos con el Vaticano. Un estudio de caso paradigmático es el del Templo Zen de la Vida, un movimiento que pasó del mercado "rojo" al "gris" y luego al "negro" como efecto de la nueva actitud de Xi hacia la religión.

Palabras clave: Religión, China, libertad religiosa, xiejiao, Templo Zen de la Vida. 
Abstract: Xi Jinping's legal and administrative reforms in the field of religion have had a great impact in Chinese society. All three segments of the religion suffered the "red market", which includes the five statecontrolled religions; the "black market" of forbidden cults (or xiejiao); and the "gray market" of churches, temples and Mosques technically illegal, but sometimes tolerated. During the Xi administration, many steps were taken to eliminate the "gray market," either by convincing congregations to join the official "red market," or by destroying places of worship and arresting local leaders. Dissident Catholic congregations were also eliminated through a combination of police repression and diplomatic agreements with the Vatican. A paradigmatic case study is represented by the Life Zen Temple, a movement that went from the "red" to the "gray" and finally to the "black" market as an effect of Xi's new attitude towards religion.

Keywords: Religion, China, Religious freedom, xiejiao, Life Zen Temple.

Citar como: Introvigne, M. (2022). Religión, “sectas” y control social en la China de Xi Jinping. Revista Internacional de Estudios Asiáticos, $1(1), 30-68$.

Fecha de recepción: 14-09-2021 | Fecha de aceptación: 21-10-2021 


\section{Introducción}

Este artículo pretende discutir cómo cambió el control estatal de la religión en China tras la llegada al poder del presidente Xi Jinping en 20122013. La situación empeoró considerablemente para todos los segmentos de la religión china, ya que la limitada liberalización de la religión que comenzó bajo Deng Xiaoping (1904-1997) después de la Revolución Cultural llegó a su fin en China.

Una de las razones que llevaron a Xi a reprimir la religión más de lo que habían hecho sus predecesores fue la creciente afluencia de nuevos movimientos religiosos procedentes del extranjero, como parte de un fenómeno más amplio de globalización religiosa. No sólo los movimientos religiosos con sede en Taiwán aumentaron sus misiones en China, sino también las iglesias evangélicas coreanas y los nuevos movimientos religiosos, así como los Testigos de Jehová.

En la primera parte del artículo, analizaré la situación desde la victoria comunista en 1949 hasta las primeras medidas introducidas por Xi Jinping. Los tres párrafos siguientes describen, utilizando la terminología de Yang Fenggang, ${ }^{1}$ los tres segmentos de la religión china y cómo se vieron afectados por las reformas de Xi: el "mercado rojo" controlado por el gobierno, el "mercado negro" de los movimientos religiosos que han sido explícitamente proscritos y prohibidos, y el “mercado gris", que incluye el mayor grupo de creyentes religiosos en China y las comunidades que no están reconocidas como legales ni explícitamente prohibidas.

En la última parte del artículo, presento un estudio de caso del Templo Zen de la Vida (生命禅院, Life Zen Temple). ${ }^{2}$ Se trata de un movimiento idiosincrásico tanto por su insistencia en ser a la vez comunista y religio-

1 Fenggang Yang, "The Red, Black, and Gray Markets of Religion in China”, Sociological Quarterly 47, no. ${ }^{\circ}$ (2006): 93-122. Y Fenggang Yang, Religion in China: Survival and Revival Under Communist Rule (New York: Oxford University Press, 2012).

2 Life Zen Temple, “新时代人类八百理念” [Ochocientas ideas para la humanidad en la nueva era], 2017. https://chanyuan.org/\#c-values-sheet1-tab1 
so como por sus experimentos sobre el amor libre. También es un buen ejemplo de los efectos de los cambios legislativos y administrativos de $\mathrm{Xi}$, ya que pasó de lo rojo a lo gris y, finalmente, en 2021, a lo negro.

\section{El control de la religión en China}

El Partido Comunista de China (PCCh) considera el ateísmo como parte de sus doctrinas fundamentales. El ateísmo se declara en muchos documentos oficiales como parte esencial e irreformable de la ideología del PCCh. ${ }^{3}$ Sin embargo, cuando el PCCh llegó al poder en 1949, era un hecho que China estaba llena de religiones. Mao Zedong (1893-1976) creía que la religión se erradicaría en China extirpando sus raíces sociales, es decir, haciendo de China un país verdaderamente comunista. Mientras tanto, las religiones, en lugar de ser desarraigadas de forma inmediata y violenta, deberían ser acompañadas tranquilamente hasta su desaparición mediante el control social, con el fin de evitar cualquier crecimiento religioso o, peor aún, una sublevación o contrarrevolución. ${ }^{4}$

El presidente Mao ordenó la expulsión de todos los misioneros extranjeros y la detención o ejecución de todos los líderes religiosos cuya oposición al régimen fuera conocida. Mao también reforzó el control sobre los musulmanes de Sinkiang y, tras invadir el Tíbet en 1950, sobre los budistas de ese país. Como ha demostrado Li Jianglin, Mao persiguió duramente a los budistas tibetanos que vivían en regiones de China distintas del Tíbet y, cuando los tibetanos del Tíbet protestaron, utilizó sus protestas como pretexto para imponer allí un régimen de persecución. ${ }^{5}$ La principal herramienta de Mao para limitar la religión fue, sin embargo, la formación de organismos religiosos estrictamente controlados por el PCCh. Los líderes de estos organismos debían ser nombrados por el $\mathrm{PCCh}$ y se les prohibía mantener cualquier contacto con organizaciones religiosas extranjeras o internacionales.

3 Michael Walsh, Stating the Sacred: Religion, China, and the Formation of the Nation-State (New York: Columbia University Press, 2020).

4 Yang, "The Red, Black and Grey", 93-122.

5 Jianglin Li, Tibet in Agony: Lhasa 1959 (Cambridge, MA: Harvard University Press, 2016). 
Por mucho que el PCCh quisiera seguirle la corriente al presidente Mao, la tarea resultó muy difícil. Para ser creíbles, los nuevos organismos religiosos deberían incluir al menos a algunos de los líderes religiosos existentes, y pocos de ellos aceptaron ser reclutados por el PCCh. Tras un complicado proceso de amenazas y halagos, finalmente el PCCh pudo establecer, entre 1953 y 1957, cinco organismos religiosos controlados por el gobierno:

1. El Movimiento Patriótico de las Tres Autonomías, o Iglesia de las Tres Autonomías (1954), un organismo unificado que incluía a todos los protestantes leales al PCCh, caracterizado por las "Tres Autonomías", es decir, "autoadministración, autoapoyo y auto propagación”, con lo que el PCCh quería decir que no se debía recibir ni aceptar ninguna ayuda de misioneros extranjeros y organismos internacionales;

2. La Asociación Budista de China (1953);

3. La Asociación Islámica de China (1953);

4. La Asociación Taoísta de China (1957);

5. El Comité Patriótico de Laicos Católicos de China (1957), que posteriormente pasó a llamarse Asociación Patriótica Católica China, es decir, la Iglesia Católica Patriótica.

Por supuesto, era difícilmente creíble que la inmensa riqueza y variedad teológica del cristianismo protestante chino pudiera reducirse a una sola iglesia. El reclutamiento de sacerdotes católicos leales al PCCh fue también una tarea difícil, encomendada en su mayoría a Xi Zhongxun (1913-2002), el padre del actual presidente Xi Jinping. El Vaticano declaró rápidamente a la Iglesia Católica Patriótica, cuyos obispos eran nombrados por el PCCh y no por Roma, cismática y no católica en absoluto. Los católicos leales a Roma pasaron a la clandestinidad y establecieron una vibrante Iglesia Católica Clandestina, el único organismo católico de China reconocido por el Vaticano hasta 2018, aunque la mayoría de sus obispos fueron arrestados y muchos murieron en la cárcel. ${ }^{6}$

6 Richard Madsen, China's Catholics: Tragedy and Hope in an Emerging Civil Society (Berkeley: University of California Press, 1998). 
Los cinco organismos oficiales nunca fueron muy populares. Sin embargo, reunir a todos los chinos que aún se consideraban religiosos en uno de los cinco cuerpos oficialmente reconocidos fue una tarea encomendada a la policía más que a los teólogos.

Al principio, los cinco organismos sólo estuvieron activos durante una década. En 1966 comenzó la Revolución Cultural. Esta persiguió con igual ferocidad tanto la religión autorizada como la no autorizada. Casi todos los lugares de culto fueron destruidos o convertidos en cuarteles o establos. Tesoros culturales se perdieron para siempre, ya que las estatuas fueron destrozadas y los cuadros y libros quemados. Miles de pastores, sacerdotes, monjes e imanes fueron asesinados, y no se toleró ninguna forma de culto o creencia. ${ }^{7}$ Incluso tener una Biblia o una estatua de Buda en casa era suficiente para ser detenido y, en varios casos, ejecutado. Al menos medio millón de creyentes, posiblemente muchos más, fueron asesinados o murieron en campos de trabajo. A principios de la década de 1970, los guardias rojos anunciaron que la religión en China había sido "borrada como el polvo". ${ }^{8}$

Sin embargo, cuando finalmente se asentó otra polvareda, la de la propia Revolución Cultural, el presidente Mao murió (en 1976) y Deng Xiaoping subió al poder (en 1978), el PCCh descubrió, para su sorpresa, que la religión no había desaparecido, a pesar de una de las peores persecuciones de la historia de la humanidad. Sólo se volvió más profundamente clandestina. Esto llevó a Deng a revisar las ideas de Mao sobre la religión. No las proclamó erróneas, sino que adoptó un calendario diferente, ya que creía que la desaparición de la religión podía requerir siglos, en lugar de meras décadas de gobierno comunista en China.

En 1982, Deng ordenó la publicación de un texto conocido como "El punto de vista y la política básicos sobre los asuntos religiosos durante el periodo socialista de nuestro país", posteriormente conocido como

7 Roderick MacFarquhar y Michael Schoenhals, Mao's Last Revolution (Cambridge: Belknap Press of Harvard University Press, 2006).

8 Yang, "The Red, Black and Grey", 101. 
“Documento $\mathrm{N}^{\circ} 19$ ". ${ }^{9}$ Los cinco organismos controlados por el gobierno fueron restaurados a su posición inicial, aunque también se reiteraron las limitaciones a las actividades religiosas, y Deng insistió en que la propaganda a favor del ateísmo debía seguir realizándose. ${ }^{10}$

De hecho, los cinco organismos nunca controlaron toda la actividad religiosa. Como escribió el sociólogo Yang Fenggang, el PCCh había creado un "mercado rojo" de religión aprobada, al que oponía un "mercado negro" de grupos declarados ilegales y perseguidos. ${ }^{11}$ La teoría sociológica, sin embargo, sostiene que ni siquiera los regímenes totalitarios son capaces de controlar totalmente la religión. Antes de 1982 existía un "mercado gris” al margen de los cinco organismos aprobados, y siguió existiendo después de esa fecha.

La era Deng fue, comparativamente, una época menos severa para la religión en la China comunista. Algunos estudiosos creen que el sistema de Deng continuó con sus sucesores, hasta que Xi Jinping accedió al poder en 2012-2013. ${ }^{12}$

Pero la situación empeoró gradualmente incluso antes de Xi. Hubo un sutil cambio de la fórmula del Documento 19 de "someter la religión a la educación socialista" ${ }^{13}$ a la redacción que prevalecía en los documentos de la década de 1990: "orientar activamente la religión para que se adapte a la sociedad socialista”, que se reflejó en las nuevas regulaciones promulgadas en 2004 y $2005 .^{14}$

9 Comité Central del Partido Comunista Chino, "Document 19: The Basic Viewpoint on the Religious Question during Our Country's Socialist Period", Traducción al inglés, 1982.

10 Fenggang Yang, "Between Secularist Ideology and Desecularizing Reality: The Birth and Growth of Religious Research in Communist China”, Sociology of Religion 65, no. ${ }^{\circ} 2$ (2004):101-19.

11 Yang, "The Red, Black and Grey".

12 Yuanxin Meng, "The New Socialism Reform or Delusion to Eradicate Religion: An Analysis of the New Religious Affairs Regulations and the Chinese Communist Party's Religious Policy during the Xi Administration", Chinese Law and Religion Monitor 11, no. ${ }^{\circ} 1$ (2018): 21-64.

13 Comité Central, "Document 19".

14 Meng Yuanxin, "The New Socialism”, 49. 
Tres acontecimientos marcaron un empeoramiento de la situación de la religión en China en el periodo comprendido entre la represión de la protesta de la plaza de Tiananmen en 1989 y el acceso de Xi al cargo de secretario del PCCh en 2012. El primero fue el ataque terrorista a Estados Unidos el 11 de septiembre de 2001, que ofreció al PCCh el pretexto para reprimir a los uigures musulmanes y a otras minorías etnorreligiosas musulmanas, alegando, falsamente, que un número muy significativo de ellos apoyaba el terrorismo (aunque algunos lo hacían, eran una ínfima minoría). Esto se debió sobre todo al inesperado éxito de los nuevos movimientos religiosos cristianos, el mayor de los cuales fue la Iglesia de Dios Todopoderoso. ${ }^{15}$ En tercer lugar, en 1999 el PCCh se enfrentó a Falun Gong, con el que había mantenido una buena relación durante varios años en el marco de la tolerancia y la promoción del Qi Gong. Falun Gong fue prohibido, y su persecución fue extrema tanto en términos de alcance como de crueldad. ${ }^{16}$

Xi Jinping se convirtió en secretario del PCCh en 2012 y en presidente de China en 2013. A veces se utiliza el término "neomaoísmo" para describir su ideología, pero el término debe manejarse con cuidado, ya que Xi nunca negó que la Revolución Cultural hubiera sido en muchos aspectos un desastre para el país, ni revocó las reformas económicas procapitalistas de sus predecesores posteriores a Mao. Sin embargo, Xi mostró algunas similitudes con Mao al reforzar la posición del secretario del PCCh, promover el culto a su propia personalidad (y, en ocasiones, a la de Mao) y reprimir la religión.

Un estudio cuidadoso de los pronunciamientos y políticas de Xi sobre la religión muestra muy claramente que él cree que se había dado demasiada latitud al desarrollo de la religión en China desde Deng. Esto condujo a un crecimiento sin precedentes del mercado gris y, peor aún, del mercado negro. Aunque sus predecesores ya habían actuado contra el mercado

15 Massimo Introvigne, Inside The Church of Almighty God: The Most Persecuted Religious Movement in China, (New York: Oxford University Press, 2020).

16 David Ownby, Falun Gong and the Future of China (New York: Oxford University Press, 2008). 
negro con ferocidad, reduciendo en gran medida la presencia de Falun Gong (pero no de la Iglesia de Dios Todopoderoso) en China, Xi adoptó nuevas medidas para reprimir las religiones prohibidas, utilizando un lenguaje violento que recuerda las campañas de la década de 1950 contra el nuevo movimiento religioso Yiguandao, cuando 820.000 "líderes y organizadores" y 13 millones de seguidores fueron detenidos o perseguidos de otra manera. ${ }^{17}$

Sin embargo, como los tiempos han cambiado desde la década de 1950, el PCCh de Xi también promovió una campaña masiva de noticias falsas destinada a justificar la persecución a nivel internacional, enrolando a los críticos de las "sectas" (algunos de ellos cristianos) y a los periodistas de Asia y Occidente como compañeros de viaje.

Xi también se dio cuenta de que la globalización religiosa había provocado una afluencia a China de misioneros extranjeros, especialmente de Corea. En 2016, hizo un llamamiento para reprimir las "infiltraciones en el extranjero por medios religiosos". ${ }^{18}$ Esto condujo a una intensificación de la represión tanto de los nuevos movimientos religiosos coreanos activos en China, como Shincheonji, Providence y la Iglesia Central Manmin, ${ }^{19}$ como de las iglesias y movimientos evangélicos coreanos algo más convencionales, como Darakbang ${ }^{20}$ y la Misión de la Buena Nueva. ${ }^{21}$

17 Yong Shao, 中國會道門 [Sectas y sociedades secretas chinas] (Shanghái: Shanghai renmin chubanshe, 1997) 452, 455. Es posible que la policía haya exagerado las cifras para sus propios fines, pero ciertamente los detenidos fueron millones. 18 Xinhua, "Xi Calls for Improved Religious Work", 24 de abril de 2016. http:// www.china.org.cn/china/2016-04/24/content_38312410.htm

19 Wangli Chen, "Manmin Central Church Believers Detained in Different Provinces”, Bitter Winter, 22 de junio de 2021c. https://bitterwinter.org/manmin-central-church-believers-detained-in-different-provinces/

20 Wangli Chen, "China Moves Against the Christian Darakbang Movement", Bitter Winter, 16 de junio de 2021b. https://bitterwinter.org/china-moves-against-the-christian-darakbang-movement/

21 Wangli Chen, "Manmin Central Church Believers Detained in Different Provinces", Bitter Winter, 11 de julio de 2021a. https://bitterwinter.org/ccp-cracksdown-on-korea-based-good-news-mission/ 
En el mismo discurso de 2016, pronunciado durante una conferencia de alto nivel sobre religión, Xi recordó a su audiencia que los miembros del PCCh son "ateos marxistas inflexibles", y que la propaganda del ateísmo siempre debe ser reforzada. ${ }^{22}$

Xi perdió la paciencia con la estrategia de Deng de acompañar a la religión a una lenta desaparición mediante un proceso que duraría décadas o incluso siglos. De hecho, decidió actuar con decisión contra los tres segmentos de la religión china.

\section{El mercado rojo}

En los términos de Yang Fenggang, al menos en la narrativa oficial del régimen, los cinco organismos aprobados son el virtuoso "mercado rojo" de la religión..$^{23}$ Cuando la propaganda china asegura que la religión en China es libre e incluso apoyada por el dinero del PCCh, se refiere a los cinco organismos controlados por el gobierno. De hecho, el fastuoso estilo de vida de algunos líderes de estos organismos parece confirmar que al menos la parte de la propaganda sobre el dinero no es falsa.

Sin embargo, la actividad de las organizaciones religiosas pertenecientes a los cinco organismos no es en absoluto libre. En primer lugar, obviamente, no se permite ninguna crítica al PCCh. En segundo lugar, se prohíbe el proselitismo y sólo se permite predicar en los lugares de culto autorizados. Cuando Rusia, con las Leyes Yarovaya, aprobó medidas similares contra el proselitismo en 2016, hubo una protesta internacional, pero pocos se dieron cuenta de que China siempre había estado en la misma situación.

En tercer lugar, hay una serie de reglamentos administrativos fastidiosos, que ponen de hecho a las comunidades religiosas autorizadas a merced de las autoridades locales del PCCh. No hace falta mucho para descubrir que se ha infringido una de estas normas, y las consecuencias pueden ser muy graves, hasta la demolición de los lugares de culto y la detención del clero.

22 Xinhua, "Xi Calls for Improved".

23 Yang, "The Red, Black and Grey". 
La norma más odiosa es la que prácticamente equipara la religión con la pornografía, y que ordena que ningún menor de 18 años pueda entrar en un lugar de culto o participar en cualquier tipo de actividad religiosa. Tras la reforma de la normativa religiosa de Xi Jinping de 2018, se aplica con mayor rigidez. Se han cerrado iglesias simplemente porque las madres entraban en ellas con sus hijos pequeños en brazos.

El "mercado rojo" se estableció originalmente para impedir la presencia en China de entidades religiosas con conexiones internacionales. Estas conexiones siguen estando prohibidas, pero se espera que las cinco organizaciones oficiales apoyen la propaganda china agasajando a los visitantes extranjeros, tratando de persuadirlos de que la religión es libre en China. También se espera que apoyen la persecución de los grupos del "mercado negro" proporcionando argumentos teológicos que confirmen que sus enseñanzas son heréticas.

Sin embargo, sería un error argumentar que todos los creyentes que participan en las actividades de la religión del "mercado rojo" son insinceros, o que la religión "oficial” sólo existe con fines de propaganda. Este puede ser el caso en áreas específicas, pero no es la regla. Hay lugares en China donde el "mercado rojo" ofrece la única oportunidad de mantener algún contacto con la religión. Los creyentes sinceros pueden decidir que aprovechar esta oportunidad es, después de todo, mejor que nada.

Sin embargo, en 2021, el centenario del Partido Comunista de China, celebrado el $1^{\circ}$ de julio, provocó una aceleración del proceso de transformación de las iglesias, templos y mezquitas del "mercado rojo" en portavoces del régimen. Los pastores protestantes de la Iglesia de los Tres Estados recibieron instrucciones de celebrar el aniversario y predicar sermones que resumieran los puntos clave del discurso de $\mathrm{Xi}$ Jinping en la celebración principal, y se les dijo que habría sanciones si se negaban a cooperar. ${ }^{24}$ Es probable que prácticas similares contribuyan a la pérdida de credibilidad de la Iglesia de las Tres Autonomías y de las asociaciones paralelas controladas por el gobierno que gestionan las demás religiones aprobadas.

24 Chunhua Zhang, "Christian Churches Ordered to Preach Xi Jinping's July 1 Speech", Bitter Winter, 14 de julio de 2021. https://bitterwinter.org/christianchurches-ordered-to-preach-xi-jinpings-july-1-speech/ 


\section{El mercado negro}

El término chino utilizado para designar a los grupos oficialmente prohibidos e incluidos en el “mercado negro" es xie jiao (邪教). Pero ¿qué son exactamente los xie jiao? Xie jiao se traduce en los documentos oficiales chinos al español como "sectas" o "sectas malignas". La traducción, sin embargo, es errónea, y está relacionada con un intento de argumentar que el problema de las "sectas" no es sólo chino, sino internacional.

De hecho, el PCCh no inventó la noción de xie jiao, sino que la heredó de la China imperial y republicana. La expresión xie jiao nació en China en la Edad Media, y una traducción más correcta es "enseñanzas heterodoxas".

Xie jiao fue utilizado por primera vez por el cortesano taoísta Tang Fu Ji (554-639) para designar al budismo, al que denunció como una herejía maligna que debía ser erradicada. ${ }^{25}$ Aunque xie jiao no se convirtió en un concepto legal plenamente desarrollado hasta finales de la era Ming, ${ }^{26}$ basado en presupuestos tanto teológicos como políticos, ${ }^{27}$ las "enseñanzas heterodoxas" se identificaron desde el siglo VII de nuestra era como movimientos religiosos que amenazaban la estabilidad y la armonía de China.

Había dos criterios principales para identificar la "heterodoxia”. En primer lugar, eran etiquetados como xie jiao movimientos milenaristas, que anunciaban el fin de este mundo y el inminente advenimiento de una nueva era, cuando una figura mesiánica -a menudo, el propio líder del movimiento- reemplazaría al emperador. En segundo lugar, a diferencia de las religiones legítimas, los xie jiao eran acusados de convertir a sus seguidores mediante el uso de "magia negra", con técnicas secretas que

25 Junqing Wu, "Words and Concepts in Chinese Religious Denunciation: A Study of the Genealogy of Xiejiao", The Chinese Historical Review 23, no. ${ }^{\circ} 1$ (2016): 8-9.

$26 \mathrm{Wu}$, "Words and Concepts".

27 Junqing Wu, Mandarins and Heretics: The Constructions of "Heresy" in Chinese State Discourse (Leiden: Brill, 2017). 
incluían hechizos, encantos, espejos mágicos y venenos. ${ }^{28}$ Aparte de la teoría china medieval de que las víctimas pueden ser rescatadas mediante el uso de "sangre de perro, un método común para disipar la brujería", ${ }^{29}$ las acusaciones de magia negra, como señaló Wu, no son tan diferentes de las afirmaciones modernas de que Falun Gong utiliza el "lavado de cerebro" para ganar adeptos, que de hecho aparecen como una versión secularizada de las antiguas acusaciones de brujería. ${ }^{30}$

La preocupación de la China imperial por los xie jiao tenía sus raíces en una tradición centenaria de movimientos milenarios chinos que intentaban superar a los gobiernos. Mientras que algunos de ellos suponían amenazas muy reales para el Imperio, otros fueron proscritos con base en una amplia variedad de consideraciones políticas y religiosas. El emperador determinaba qué enseñanzas eran "heterodoxas", y las listas de xie jiao podían cambiar por motivos políticos. Por ejemplo, el cristianismo en su conjunto fue clasificado como xie jiao en 1725 , pero fue retirado de la lista en 1842 , debido a la presión política y militar de Occidente. ${ }^{31}$

Los gobiernos republicano y comunista heredaron esta antigua noción y política. La categoría de xie jiao se utilizó tanto en Taiwán, durante el periodo de la Ley Marcial y aún después, como en la China continental en la década de 1950 para las ya mencionadas persecuciones masivas de Yiguandao. Sin embargo, xie jiao no fue el principal término utilizado durante estas campañas. Como ha señalado David Palmer, el PCCh prefería definir a los grupos perseguidos como "sociedades secretas reaccionarias" (fandong buidaomen) o "sociedades secretas feudales" (fengjian buidaomen), etiquetas que reflejaban la idea de Mao de que, en realidad, algunas sociedades secretas habían desempeñado en la historia china un papel

$28 \mathrm{Wu}$, Mandarins and Heretics, 57-92.

$29 \mathrm{Wu}$, Mandarins and Heretics. 63.

$30 \mathrm{Wu}$, Mandarins and Heretics. 156-157.

31 Vincent Goossaert, y David A. Palmer, The Religious Question in Modern China (Chicago: University of Chicago Press, 2011), 27-31. 
progresista y no reaccionario. ${ }^{32}$ Huidaomen se utilizó posteriormente para subrayar que los grupos prohibidos, aunque pudieran utilizar la máscara de la religión, no eran "realmente" religiosos, eran similares al crimen organizado y quedaban fuera del ámbito de la libertad religiosa teóricamente garantizada por la Constitución china a las actividades religiosas "normales".

Sin embargo, xie jiao volvió a ser el término más utilizado en la década de 1990. David Palmer ${ }^{33}$ y Edward Irons ${ }^{34}$, creen que la vuelta a la prevalencia de la etiqueta xie jiao, que volvió a ser preferida a la de buidaomen, estuvo determinada por el intento del PCCh de suscitar la simpatía tanto de quienes se oponían a las "sectas" en Occidente como de las principales iglesias cristianas, que temían la competencia de los nuevos movimientos religiosos cristianos que consideraban heréticos. Sin embargo, una teoría sistemática de los xie jiao como "sectas malignas", una traducción, como se mencionó anteriormente, adoptada por el propio régimen chino, pero de hecho menos precisa que las "enseñanzas heterodoxas", surgió solo con los incidentes de finales de la década de 1990 que persuadieron al PCCh de que Falun Gong era un competidor y enemigo peligroso. ${ }^{35}$

Esto generó la inclusión de un nuevo delito, "usar” un xie jiao, en el Código Penal chino en 1999; la creación de una unidad policial especial llamada Oficina 610 (desde la fecha de su establecimiento, el 10 de junio de 1999) para tratar con los xie jiao; y el establecimiento en toda China y en algunos centros de la diáspora china en el extranjero de sucursales de una Asociación China Anti-Xie-Jiao (llamada en inglés "China Anti-Cult Association”), directamente conectada con el PCCh. Cuando estas medi-

32 David Alexander Palmer, "Heretical Doctrines, Reactionary Secret Societies, Evil Cults: Labelling Heterodoxy in 20th-Century China”, en Chinese Religiosities: The Vicissitudes of Modernity and State Formation, ed. por Mayfair Yang (Berkeley CA: University of California Press, 2012), 113-34.

33 Palmer, "Heretical Doctrines", 113-34.

34 Edward Irons, "The List: The Evolution of China's List of Illegal and Evil Cults", The Journal of CESNUR 2, no. ${ }^{\circ} 1(2018)$ : 33-57.

35 Irons, "The List", 41. 
das entraron en vigor, ya se había recuperado la antigua práctica de compilar listas oficiales de xie jiao, con la primera lista nacional publicada en 1995. ${ }^{36}$ El 19 de marzo de 2018, cuando Xi Jinping pidió una represión más eficaz del xie jiao, se disolvió la Oficina Central 610 y su personal y actividades se transfirieron a la Comisión Central de Asuntos Políticos y Jurídicos y al Ministerio de Seguridad Pública, ${ }^{37}$ aunque se siguió haciendo referencia a las unidades policiales locales especializadas contra los xie jiao utilizando el número 610.

El artículo 300 del Código Penal chino convirtió el "uso" de un xie jiao en un delito castigado con penas de cárcel de tres a siete años "o más". Aquí, de nuevo, Xi Jinping intervino y pidió sanciones más duras. La enmienda IX al Código Penal de la República Popular China fue aprobada en la 16 ${ }^{a}$ Sesión del Comité Permanente de la 12a Asamblea Popular Nacional el 29 de agosto de 2015, y entró en vigor el 1 de noviembre de 2015. Modificó el artículo 300, tanto al incluir en su ámbito de aplicación los delitos menores, castigados en algunos casos con menos de tres años de prisión, como al elevar la pena máxima por participación grave en un xie jiao a la cadena perpetua. ${ }^{38}$

Lo que era aún más importante era determinar qué significa exactamente "utilizar un xie jiao" en el contexto del artículo 300. El llamamiento de Xi Jinping a una represión más decidida del xie jiao se tradujo en la "Interpretación del Tribunal Popular Supremo y la Fiscalía Popular Suprema sobre varias cuestiones relativas a la ley aplicable en casos penales como los de uso de xie jiao para sabotear la aplicación de la ley”. Fue aprobada el 8 de diciembre de 2016, por la 58a reunión de la 12a sesión del Comité

36 Irons, "The List", 33-57.

37 Edward Irons, "Importantes cambios en las estructuras encargadas de combatir a los xie jiao en China”, Bitter Winter, 25 de febrero de 2019. https://es.bitterwinter.org/cambios-en-las-estructuras-encargadas-de-combatir-a-los-xie-jiao/ 38 Massimo Introvigne, James T. Richardson y Rosita Šoryte, "Would the Real Article 300 Please Stand Up? Refugees from Religious Movements Persecuted as Xie Jiao in China: The Case of The Church of Almighty God", The Journal of CESNUR 3, no 5 (2019): 11-12. 
de Fiscales de la Fiscalía Popular Suprema, y el 4 de enero de 2017, por la 1706ª sesión del Comité de Adjudicación del Tribunal Popular Supremo. Fue promulgada el 25 de enero de 2017 y entró en vigor el 1 de febrero de 2017.

Aunque la fórmula "utilizar un xie jiao para sabotear la aplicación de la ley” puede hacer pensar que el artículo 300 se refiere únicamente a quienes "utilizan" un movimiento religioso prohibido para cometer delitos graves, la lista detallada de delitos del documento de 2017 aclara que estos "delitos" incluyen todas las actividades religiosas normales, como asistir a una reunión de un xie jiao, hacer proselitismo entre familiares y compañeros de trabajo, e incluso tener en casa una cierta cantidad de libros o vídeos de un grupo prohibido. La interpretación oficial de 2017 del artículo 300 también permitía utilizarlo contra grupos que no formaban (o aún no formaban) oficialmente parte de la lista de los xie jiao pero que eran considerados como tales por los fiscales, como los Testigos de Jehová. ${ }^{39}$

No todas las decisiones de los tribunales chinos se publican en línea, pero millones de ellas están en lo que supone la mayor base de datos de jurisprudencia del mundo, aunque en 2021 se eliminaron miles de decisiones para evitar que las organizaciones de derechos humanos de Occidente las utilizaran para criticar a China. ${ }^{40}$ Sin embargo, aún queda un gran número de decisiones publicadas en las que los miembros de xie jiao fueron condenados a largas penas de cárcel (a menudo superiores a siete años) con base en el artículo 300. En 2019, antes de que muchas de ellas desaparecieran, mis colegas James T. Richardson y Rosita Šorytė y yo descargamos y guardamos las decisiones que condenaban a unos 200 miembros de la Iglesia de Dios Todopoderoso y publicamos un estudio sobre ellas. ${ }^{41}$

De estas decisiones se desprende que "usar un xie jiao" se interpreta como "estar activo en un xie jiao" en cualquier capacidad. Aunque los líderes reciben penas más duras, no es en absoluto necesario ser un líder

39 Introvigne, Richardson y Šorytè, "Would the Real", 13-19.

40 Feng Yang, "The Great Purge of China Legal History”, Bitter Winter, 28 de junio de 2021. https://bitterwinter.org/the-great-purge-of-china-legal-history/ 41 Introvigne, Richardson y Šorytè, "Would the Real”. 
para ser reconocido como culpable de haber "utilizado un xie jiao" en virtud del artículo 300. De hecho, haber sido encontrado en posesión de literatura de un xie jiao, o haber intentado convertir a otros a un xie jiao, han sido considerados como prueba suficiente de ser culpable del delito castigado por el artículo 300. En reacción a nuestro estudio, que ha sido reconocido por los académicos chinos que son miembros del PCCh también, algunos de ellos han recomendado a las autoridades chinas una aplicación menos dura del artículo $300,{ }^{42}$ lo que parece sin embargo poco probable. ${ }^{43}$

En China se ofrecen recompensas monetarias a quienes faciliten a la policía los nombres de los miembros de los xie jiao, así como información que conduzca a su detención. De nuevo, se ofrecen recompensas más altas para los "líderes", pero también se pagan recompensas a quienes denuncian a un simple devoto. Las autoridades chinas competentes y los medios de comunicación locales publican, o publicaban, algunas de estas tablas de recompensas en Internet.

Que los xie jiao son ilegales, y que el PCCh las considera organizaciones peligrosas, está muy claro. Mucho menos clara está la definición de xie jiao, algo en lo que también han trabajado constantemente los burócratas de Xi Jinping bajo el impulso del propio presidente. El intento más reciente hasta la fecha de mejorar una definición anterior a Xi Jinping del ańo 2000, incorporando al mismo tiempo sus criterios, dio lugar a la regla 1 del ya mencionado documento interpretativo de 2017. Los xie jiao fueron definidos como "organizaciones ilegales que, mediante el uso fraudulento de la religión, el Qi Gong o cualquier otro nombre, divinizando y promoviendo a sus cabecillas, o fabricando y difundiendo

42 Xinzhang Zhang, "The Potential Illegitimacy of the PRC's Effort to Distinguish Xie Jiao from 'Cult' or 'Destructive Cult", Alternative Spirituality and Religion Review 11, no 1 (2020): 81-95.

43 Massimo Introvigne, James T. Richardson y Rosita Šoryte, "Prophecy, Passports, and Persecution: Church of Almighty God Asylum Cases, 2015-2021", The Journal of CESNUR 5, no 3 (2021): 3-135. 
falacias supersticiosas y otros medios para confundir y engañar a otros (...), controlan a los miembros del grupo y perjudican a la sociedad". ${ }^{44}$

En la práctica, estas definiciones tan amplias significan que los grupos que se consideran xie jiao son los que se incluyen en las listas de xie jiao que se actualizan periódicamente, una vez por las autoridades nacionales y, más recientemente, por las autoridades o fiscales locales, que luego remiten sus deliberaciones a la Asociación China Anti-Xie-Jiao para su publicación nacional.

En la actualidad, existen diferentes enfoques de la cuestión del xie jiao dentro del propio PCCh. Los pastores de la Iglesia de las Tres Autonomías, que suelen ser leales al PCCh, se apoyan en una venerable tradición cuando insisten en que los xie jiao deben ser definidos como grupos heréticos que niegan las verdades básicas de las religiones tradicionales. A pesar del marxismo del partido, creen que pueden persuadir al PCCh de que el único antídoto contra la mala religión es la "buena". Esta noción presupone que es posible definir la "mala religión". Dado que grupos cristianos como la Iglesia de Dios Todopoderoso ocupan ahora un lugar destacado en el discurso chino sobre xie jiao, la norma propuesta es la interpretación protestante de la Biblia. Los grupos "no bíblicos" son xie jiao. Los pastores son menos competentes cuando se trata de criticar a grupos no cristianos como Falun Gong, pero pueden afirmar, analógicamente, que representan distorsiones heréticas de las Tres Enseñanzas (budismo, confucianismo y taoísmo). ${ }^{45}$

Resulta algo paradójico que un Estado oficialmente irreligioso pueda considerar seriamente la posibilidad de decidir qué grupos religiosos deben ser reprimidos basándose en criterios como la naturaleza de Jesucristo o la doctrina tradicional de la Trinidad. Sin embargo, hay quienes en el PCCh creen que, aunque la religión acabe desapareciendo en un futuro lejano, por el momento, la mejor manera de erradicar los xie jiao es promover el cristianismo progubernamental en la forma de la Iglesia de las Tres Autonomías y confiar en la propaganda de sus pastores.

44 Introvigne, Richardson y Šoryte, "Would the Real”, 3-86.

45 Zhang, "The Potential”, 81-95. 
Un segundo enfoque, representado por varios académicos chinos, la mayoría de ellos miembros del PCCh, especializados en el estudio y la crítica de los xie jiao, sostiene que las "sectas" son un problema universal, no sólo chino. Algunos académicos se dedicaron a promover las traducciones de obras antisectas publicadas en Estados Unidos y Europa, e incluso invitaron a desprogramadores a China. Sin embargo, al final se dieron cuenta de que este enfoque tenía el inconveniente de crear listas larguísimas de xie jiao, mientras que el PCCh y la policía preferirían concentrar sus recursos en los pocos que consideran realmente peligrosos para el Partido y para la estabilidad social de China. De ahí la traducción posterior de xie jiao como "sectas destructivas", un término también utilizado por los movimientos antisectas occidentales, o (más comúnmente) como "sectas malignas", con la implicación de que no todas las "sectas" son realmente "destructivas" o "malignas". 4647

Algunos académicos chinos importaron del movimiento antisectas occidental la noción de lavado de cerebro como el carácter distintivo de las "sectas destructivas". Esta fue otra paradoja, ya que la propia palabra "lavado de cerebro" fue acuñada originalmente por la inteligencia estadounidense durante la Guerra Fría para apoyar la propaganda anti-China. El lavado de cerebro era algo que hacían los malvados comunistas chinos. ${ }^{48}$ Los tribunales chinos, incluido el Tribunal Supremo del Pueblo, se mantuvieron al margen de las controversias sobre el lavado de cerebro, y describieron a los xie jiao como grupos que difunden "superstición", que se define como algo opuesto a la ciencia y al socialismo, y diferente de la 46 Qingping Chen, "Reflection on the Definition of Cults and Its Related Problems" (Ponencia presentada en la conferencia The Question of Xiejiao in China and the Case of the Church of Almighty God. Universidad de Hong Kong, 15 y 16 de septiembre de 2017).

$47 \mathrm{Tao} \mathrm{Xu}$, "The Comparison and Dialogue of Definitions of Cult between China and America" (Ponencia presentada en la conferencia The Question of Xiejiao in China and the Case of the Church of Almighty God. Universidad de Hong Kong, 15 y 16 de septiembre de 2017).

48 Introvigne, Massimo, [de próxima publicación], Brainwashing: Reality or Myth? (Cambridge, Reino Unido: Cambridge University Press, 2022). 
religión genuina. De hecho, los xie jiao también se definen como movimientos "pseudorreligiosos".

Como observó el académico estadounidense J. Gordon Melton, es importante destacar que para el PCCh y los tribunales chinos los xie jiao no son religiones. ${ }^{49}$ Las objeciones occidentales sobre la libertad religiosa se descartan como irrelevantes. Las autoridades chinas responderían que la libertad religiosa está garantizada por la Constitución china, pero los xie jiao no tienen nada que ver con la religión.

Esta es una actitud antigua, y no sólo china. Normalmente, los hostiles a las "sectas", cuando se enfrentan a la objeción de que la represión de las "sectas" viola la libertad religiosa, responden que las "sectas" no son religiones. Esta fue la posición del campo antisectas en las "guerras de sectas" de finales del siglo XX. Pero la posición se remonta al menos a un siglo antes de las "guerras de sectas". Era difícil negar que en la América del siglo XIX los mormones eran discriminados y perseguidos. En 1877, en un artículo de la popular revista Scribner's Monthly, el antimormón John Hanson Beadle confesó que

los estadounidenses no tienen más que una religión nativa [el mormonismo] y ésta es la única excepción aparente a la regla estadounidense de tolerancia universal [...]. De esta anomalía se ofrecen dos explicaciones: una, que los americanos no son realmente un pueblo tolerante, y que lo que se llama tolerancia es sólo tal hacia nuestro protestantismo común, o cristianismo común; la otra, que algo peculiar del mormonismo lo saca de la esfera de la religión. ${ }^{50}$

La observación de Beadle mantenía al lector como rehén, obligándolo a concluir que el mormonismo no era una religión. Sólo al afirmar que el mormonismo no era "realmente" una religión se podía conciliar la imagen de los Estados Unidos como país de la libertad religiosa con la realidad americana de la discriminación antimormona.

49 J. Gordon Melton, "Xiejiao, Cults, and New Religions: Making Sense of the New Un-Sinicized Religions on China's Fringe" (Ponencia presentada en la conferencia Sinicization of Religion in China: From Above and Below, University of California, San Diego, marzo 2018).

50 John Hanson Beadle, “The Mormon Theocracy”, Scribner's Monthly, 14, n. 3 (1877): 391. 
Sin embargo, en la América del siglo XIX esto no era más que un recurso retórico, como lo es en la China contemporánea para los xie jiao. ¿Quién decide que una religión es "auténtica" y otra sólo "pretende" ser una religión? Como afirmó el sociólogo Larry Greil en 1996, la "religión” no es "una característica inherente a ciertos fenómenos, sino (...) un recurso cultural por el que pueden competir grupos de interés". ${ }^{1}$ En la China imperial, el emperador decidía en última instancia si un movimiento religioso era una religión "real" o un xie jiao. En la China de Xi Jinping, el PCCh, como nuevo emperador, decide qué grupos son xie jiao. Son sacados de la esfera de la libertad religiosa y de los derechos humanos. Sus miembros son, de hecho, deshumanizados. Deberían ser, de hecho, según el propio eslogan del PCC, "totalmente erradicados como los tumores". Los tumores no tienen derechos y sólo pueden ser erradicados mediante la violencia.

\section{El mercado gris}

En 2006, Yang Fenggang afirmaba que el mercado gris era, con mucho, el mayor segmento de la religión china, ${ }^{52}$ y es a este segmento al que dirijo ahora mi atención, señalando que las cosas han cambiado en la segunda década del siglo XXI con respecto a 2006, debido a las medidas de Xi Jinping, y que muchos de los comentarios que siguen son míos, y no pueden atribuirse a Yang.

Yang es un seguidor de la teoría de la economía religiosa, desarrollada principalmente por el sociólogo estadounidense Rodney Stark. Uno de sus principales principios es que, incluso para los regímenes totalitarios, es imposible controlar totalmente la religión. ${ }^{53}$ Como aprendieron antes que el PCCh los emperadores romanos que intentaron suprimir el cristianismo, la religión “oficial” (el mercado rojo) sólo es atractiva

51 Arthur L. Greil, “Sacred Claims: The 'Cult Controversy' as a Struggle over the Right to the Religious Label”, en The Issue of Authenticity in the Study of Religion, ed. por David G. Bromley y Lewis F. Carter (Greenwich, CT: JAI Press), 48. 52 Yang, "The Red, Black and Grey”.

53 Rodney Stark y Wang Xiuhua, A Star in the East: The Rise of Christianity in China (West Conshohocken, PA: Templeton Press, 2015). 
para un segmento limitado de la población (aunque este segmento no es en absoluto insignificante), y siempre habrá quienes estén dispuestos a arriesgar su vida para seguir una religión del mercado negro. Por otro lado, no todo el mundo está dispuesto a poner la vida en juego por la religión. Yang sostiene que cuando la gente no encuentra satisfacción en el mercado rojo y no está dispuesta a arriesgar el castigo asociado al mercado negro, florece un mercado gris. ${ }^{54}$

Podemos distinguir seis formas de religión del mercado gris en China.

La primera incluye las actividades realizadas por las organizaciones del mercado rojo fuera de los límites fijados por el PCCh. Las organizaciones aprobadas por el gobierno son más complicadas de lo que podemos creer a primera vista. Por ejemplo, está permitido asistir a un servicio cristiano en una iglesia protestante controlada por el gobierno, o a una misa en una iglesia de la Asociación Patriótica Católica oficial, o ir el viernes a una mezquita de la Asociación Islámica de China. Sin embargo, llevar a los niños menores está prohibido. Permitir que los menores entren en un lugar de culto del mercado rojo no convierte a la organización responsable de ello en una xie jiao, pero puede hacer que la comunidad pierda su estatus de aprobada, y pase del mercado rojo al mercado gris. Las consecuencias, como es típico del mercado gris, pueden ser imprevisibles. Algunas autoridades locales pueden preferir mirar hacia otro lado, otras pueden detener a alguien o incluso demoler el lugar de culto.

En el segundo segmento está el enorme ámbito de las "iglesias domésticas” cristianas (protestantes). El término "iglesia doméstica” es algo engañoso. Algunas cuentan con miles de miembros y no se reúnen necesariamente en casas particulares. La noción de "iglesia doméstica” sólo puede definirse negativamente. Una iglesia doméstica es una organización protestante china que no está afiliada a la Iglesia de las Tres Autonomías, y que al mismo tiempo no está prohibida como xie jiao. ${ }^{55} \mathrm{~A}$ veces, esto puede llevar a confusiones, ya que algunos grupos

54 Yang, "The Red, Black and Grey".

55 Carsten T Vala, The Politics of Protestant Churches and the Party-State in China: God above Party? (London: Routledge, 2018). 
catalogados como xie jiao son teológicamente muy cercanos a la mayoría de las iglesias domésticas y, en cualquier caso, no hay definiciones unánimemente aceptadas para "cristiano" o "protestante."

Otra cuestión delicada es saber cuántos chinos forman parte del movimiento de las iglesias domésticas. La mayoría de las estimaciones mencionan cifras entre 20 y 35 millones. Algunas fuentes misioneras cristianas occidentales sugieren cifras mucho más altas, pero normalmente no logran convencer a los estudiosos. ${ }^{56}$

Vala observó que el PCCh está mal equipado para hacer frente a miles de iglesias domésticas y (al menos hasta 2018) la represión se llevó a cabo de forma selectiva. ${ }^{57}$ Solo se persiguió a las iglesias domésticas que cruzaron ciertas "líneas rojas" no escritas, que ordenan que deben seguir siendo pequeñas (el aumento de las megaiglesias urbanas es una de las causas de las nuevas restricciones de Xi Jinping) y locales (no se toleran las organizaciones y redes nacionales), no invitar a predicadores extranjeros, permitir que las autoridades vigilen sus actividades y evitar cualquier crítica al PCCh y a la Iglesia de las Tres Autonomías. ${ }^{58}$

El hecho es que varias iglesias domésticas muy visibles cruzaron estas líneas rojas, lo que llevó a la detención y condena a fuertes penas de cárcel de sus pastores. Wang Yi, el pastor de la popular Iglesia del Pacto de la Lluvia Temprana en Chengdu, fue acusado de subversión ${ }^{59}$ y condenado a nueve años de cárcel en 2019.

La tercera área del mercado gris incluye a los "objetores de conciencia” católicos. Se trata de un nuevo fenómeno que comenzó en 2018, cuando el Vaticano firmó un acuerdo con el gobierno chino (renovado en 2020), cuyo texto sigue siendo secreto, pero cuyo objetivo era acabar con la separación entre la Iglesia Patriótica controlada por el régimen y la Iglesia

56 Stark y Wang, A Star in the East.

57 Vala, The Politics.

58 Vala, The Politics.

59 Zhangjin Yao, "El Partido Comunista Chino fabrica evidencia para acusar al pastor Wang Yi”, Bitter Winter, 25 de junio de 2019. https:/es.bitterwinter.org/ el-pcch-fabrico-evidencia-para-acusar-al-pastor-wang-yi/ 
Clandestina leal a Roma. El Vaticano aconsejó a los católicos que se unieran a la Iglesia Patriótica, cuyos obispos seguirán siendo seleccionados por el PCCh, pero nombrados formalmente por el papa. Un número considerable de católicos, entre ellos varios obispos y cientos de sacerdotes, afirmaron que no podían aceptar el acuerdo por razones de conciencia, y que no se unirían a la Iglesia Patriótica, un organismo controlado por un Partido Comunista ateo y utilizado para los propios fines del Partido.

En sus “Directrices” para interpretar el acuerdo, publicadas en 2019, el Vaticano declaró que, si bien no apoya ni fomenta la objeción de conciencia, los objetores siguen siendo católicos de pleno derecho, y la Santa Sede espera que China los trate con "respeto" ${ }^{60}$ En cambio, son arrestados rutinariamente, lo que alimenta las críticas al acuerdo de 2018 entre los católicos escépticos sobre la buena voluntad de las autoridades chinas para permitir que exista una Iglesia católica en China que no esté totalmente controlada por el régimen.

El cuarto segmento incluye los templos budistas y taoístas no afiliados a la Asociación Budista de China y a la Asociación Taoísta de China. Muchos de ellos se basan en devociones locales, y se construyen con las donaciones de expatriados ricos que fueron a Occidente o a Taiwán desde un determinado pueblo o provincia. Hay una serie de razones económicas y políticas por las que el PCCh dejó que estos templos locales existieran durante décadas, y rara vez desafiaron al régimen, aunque siempre fue posible que se produjeran ocasionales represiones.

El quinto segmento del mercado gris fue identificado por Yang como el que incluye a los grupos que un sociólogo occidental puede identificar como religiosos, pero que sobreviven en China afirmando que no son religiosos en absoluto, sino que forman parte de la ciencia, la cultura, la medicina tradicional o el folclore. Tras el caso de Falun Gong, otros grupos de Qi Gong comenzaron a ser sospechados. El Consejo de Investigación Científi-

60 Santa Sede. "Orientaciones pastorales sobre el registro civil del clero en China”. 28 de junio de 2019. https://press.vatican.va/content/salastampa/es/bollettino/ pubblico/2019/06/28/tex.html_ 
ca del Qi Gong de China, que en su día fue aprobado por el gobierno, fue dado de baja en 2003, aunque el Qi Gong como tal nunca fue prohibido. ${ }^{61}$

La Nueva Era llegó a China a través de Taiwán y, como argumenta Paul Farrelly, al principio fue más o menos tolerada siempre que se presentara como no religiosa y no desafiara al PCCh. ${ }^{62}$ Algunos estudiosos creen que la mayoría de la población china participa en prácticas "espirituales" que se presentan como algo distinto a la religión. ${ }^{63}$ También forman parte del mercado gris.

La sexta forma del mercado gris fue identificada por Yang como el culto religioso al presidente Mao, que debería considerarse como algo más que una curiosidad. Como veremos en el siguiente párrafo, también hubo y hay otros grupos que ofrecen combinaciones de maoísmo y espiritualidad. Puede que hayan sido tan tolerados que en su día formaron parte del mercado rojo, pero la tolerancia se está agotando en la China de Xi Jinping, y ahora forman parte del mercado gris en el mejor de los casos.

De hecho, las fronteras entre el mercado rojo, el negro y el gris son porosas. Los grupos del mercado rojo pueden incurrir en la ira del régimen y pasar al mercado gris o incluso al negro. Los grupos del mercado gris en China pueden molestar al régimen por diversas razones y acabar en el mercado negro, es decir, en la lista de los xie jiao.

Sin embargo, existe una distinción legal muy clara entre el mercado gris y el negro. Estar activo en un grupo del mercado gris que no figura en la lista de xie jiao no es un delito en sí mismo, aunque los devotos pueden ser acusados de infringir diferentes tipos de normas, acosados de muchas maneras e incluso arrestados. En algunas circunstancias, ni siquiera el mercado rojo es completamente seguro. Pero ser activo en un grupo de xie jiao del mercado negro es un delito castigado por el Código Penal chino. No es necesario

61 David Alexander Palmer, Qigong Fever: Body, Science, and Utopia in China (New York: Columbia University Press, 2007)

62 Paul Farrelly, "Spiritual Revolutions: A History of New Age Religion in Taiwan” (Tesis de Doctorado. Universidad Nacional de Australia, Canberra, 2017). 63 Adam Yuet Chau, Religion in China: Ties That Bind, Oxford, UK y Medford, MA: Polity Press, 2019. 
acusar a los miembros de un xie jiao de otros delitos para encarcelarlos. Ser activo en un xie jiao es suficiente. El PCCh puede utilizar un enfoque de palo y zanahoria con los grupos del mercado gris e incluso del mercado rojo. En cambio, con el mercado negro el enfoque es de palo y no de zanahoria.

También hay más palo para el mercado gris desde que entró en vigor en 2018 el nuevo Reglamento de Asuntos Religiosos de 2017, que traduce fielmente el enfoque de Xi Jinping sobre la religión. ${ }^{64} \mathrm{El}$ reglamento proclama solemnemente que las religiones deben "aplicar los valores socialistas fundamentales" ${ }^{65}$ No hay lugar para las religiones que no estén dispuestas a predicar el socialismo y la ideología del PCCh. En segundo lugar, hay una definición ampliada, aunque vaga, de "extremismo religioso", posiblemente importada de Rusia. ${ }^{66}$ "Propagar, apoyar y financiar el extremismo religioso" ${ }^{67}$ está severamente castigado, y puede llevar a tratar como xie jiao a comunidades religiosas no incluidas en la lista de los xie jiao. En tercer lugar, existen normas estrictas para la construcción de nuevos lugares de culto. En cuarto lugar, existe una estricta prohibición de viajar al extranjero con fines religiosos, o de dirigir escuelas religiosas en China, para los grupos que no forman parte del mercado rojo oficial. ${ }^{68}$

Una de las partes más peligrosas de la ley es la que permite el uso de locales distintos de iglesias, mezquitas o templos como "lugares de culto temporales" sólo con la aprobación explícita de las autoridades locales. ${ }^{69}$ Esto llevó, por ejemplo, a la empresa arrendadora que alquilaba un piso de un edificio en Pekín a la Iglesia de Zion, una gran iglesia doméstica, a cancelar el contrato el 20 de agosto de 2018. El contrato era extremadamente rentable para el arrendador, pero el alquiler de un local distinto al de una

64 Consejo de Estado de China, "Religious Affairs Regulation 2017”, Traducción al inglés por China Law Translate, 2017.

65 Consejo de Estado de China, "Religious Affairs”, art. 4, no .2.

66 Véase Rosita Šoryte, “Labeling Scientology: 'Cult,' 'Fringe,' 'Extremist,' or Mainstream?”, The Journal of CESNUR 5, no. ${ }^{\circ} 4$ (2021): 64-67.

67 Consejo de Estado de China, "Religious Affairs", art. 4, N 4.

68 Consejo de Estado de China, "Religious Affairs", art. 41.

69 Consejo de Estado de China, "Religious Affairs”, art. 35. 
iglesia a un grupo religioso está ahora prohibido si no está explícitamente aprobado por las autoridades como medida "temporal". En el caso de la Iglesia de Zion, el contrato de alquiler era con Beijing Jianweitang Culture Co, Ltd., una empresa cultural constituida por miembros de la Iglesia de Zion, pero que entidades no religiosas alquilen espacios para el culto religioso también está prohibido por la nueva ley. ${ }^{70}$

Hay varias limitaciones más, pero estas son las más efectivas y muestran el ambicioso plan de Xi Jinping de eliminar el mercado gris de forma gradual, obligando a algunas comunidades a entrar en el mercado rojo y desterrando a otras a la oscuridad exterior del mercado negro.

\section{Un estudio de caso: El Templo Zen de la Vida}

El Templo Zen de la Vida es un caso interesante de la parábola de un grupo que, bajo Xi Jinping, pasó del mercado rojo al gris y luego al negro. Antes de Xi Jinping, había un pequeño sector del mercado rojo que estaba fuera de las cinco asociaciones religiosas aprobadas. Incluía grupos "cuasi religiosos" que se consideraban parte del marxismo y que cultivaban diferentes ramas de la filosofía marxista y maoísta, aunque su ideología también incluía referencias religiosas. Un ejemplo son los diferentes grupos que rechazaban la teoría de la relatividad de Albert Einstein (18791955) por considerarla ciencia burguesa incompatible con el materialismo dialéctico marxista. El presidente Mao mostró cierta simpatía por este movimiento, aunque Zhou Enlai (1898-1976), que admiraba mucho a Einstein, intentó frenarlo. Paradójicamente, aunque eran ostensiblemente marxistas, los grupos antirrelatividad incorporaron en sus críticas a la relatividad creencias casi religiosas sobre la parapsicología y las energías ocultas. $^{71}$

Tras la muerte de Mao, los grupos antirrelatividad dejaron de representar la ortodoxia del régimen, pero fueron tolerados como una curiosidad

70 Gang Feng, "Cómo las autoridades desmantelaron la Iglesia de Zion emplazada en Pekín”, Bitter Winter, 16 de septiembre de 2018. https://es.bitterwinter.org/ autoridades-desmantelaron-la-iglesia-de-zion/

71 Mengyao Liu, "Anti-Einstein Relativity Research Association Banned As a 'Cult”, Bitter Winter, 13 de julio de 2021. https://bitterwinter.org/anti-einstein-relativity-research-association-banned-as-a-cult/ 
inofensiva, parte de un segmento muy especial del mercado gris. Al fin y al cabo, eran buenos comunistas y muchos eran miembros del PCCh. Bajo $\mathrm{Xi} \mathrm{Jinping,} \mathrm{tanto} \mathrm{la} \mathrm{referencia} \mathrm{a} \mathrm{las} \mathrm{teorías} \mathrm{más} \mathrm{controvertidas} \mathrm{de} \mathrm{Mao} \mathrm{(lo}$ que podría implicar una crítica a los líderes posteriores a Mao, incluido el actual presidente) como la crítica a la ciencia académica principal eran mucho menos toleradas. El 2 de julio de 2021, el principal grupo antirrelatividad y parapsicológico, la Asociación de Investigación de la Relatividad de Pekín, fue prohibido oficialmente, los medios de comunicación del PCCh lo llamaron xie jiao, todas sus sucursales provinciales y locales fueron allanadas por la policía, y varios miembros fueron llevados a comisarías locales. ${ }^{72}$

Otra espectacular redada policial de 2021 concluyó con la caída en el inframundo de los xie jiao de otro movimiento que, de forma aún más clara, había intentado combinar el maoísmo con la religión.

El 28 de abril de 2021, a partir de la 1:00 de la madrugada, la Seguridad Pública y agentes de la unidad especializada en la lucha contra el xie jiao empezaron a hacer redadas en los dos asentamientos comunales del Templo Zen de la Vida (生命禅院, Life Zen Temple), ${ }^{73}$ situados en zonas remotas del condado de Tongzi y del condado de Anlong, en la provincia de Guizhou. A las 6:30 de la mañana, ya habían tomado el control de los dos locales, donde vivían unos 100 devotos de 13 provincias diferentes. Fue una redada clásica contra una "secta", aclamada por la policía como un éxito total (he reconstruido el incidente basándome en los comunicados de prensa de la Seguridad Pública de Guizhou).

Los agentes reunieron a los miembros del Templo Zen de la Vida, les leyeron un comunicado en el que se decía que su movimiento había sido prohibido, y procedieron a llevárselos a todos de las comunas para desprogramarlos. Según los agentes, la mayoría se resistió y gritó que prefería morir antes que abandonar la comunidad, pero ninguno de los devotos recurrió a la violencia. Al cabo de tres meses, según la Seguridad Pública

72 Liu Mengyao, “Anti-Einstein”.

73 Life Zen Tample, “新时代人类八百理念” [Ochocientas ideas para la humanidad en la nueva era], 2017. 
de Guizhou, la mayoría de los miembros habían sido desprogramados y confiados al cuidado de familiares. Su "reeducación" continuaría en casa.

Esto, según la Seguridad Pública, no era el fin del Templo Zen de la Vida. Mantienen más de 2.000 miembros, la mayoría de ellos escondidos en algún lugar de China, y su líder vive a salvo en Canadá. La caza de la policía especializada para localizar a los devotos restantes en China continúa.

El caso del Templo Zen de la Vida confirma una tendencia reciente sobre los xie jiao que he mencionado anteriormente. Hay grupos que no están incluidos en la lista nacional de los xie jiao, sino que son prohibidos por decretos de las autoridades locales a nivel provincial, pero luego son denunciados como xie jiao por la Asociación China Anti-Xie-Jiao, y a todos los efectos prácticos pasan a formar parte de la lista nacional.

El Templo Zen de la Vida tiene una larga y, de hecho, extraordinaria historia. Su fundador, Zhang Zifan, conocido por sus seguidores como Xuefeng, nació el 17 de julio de 1957 en la aldea de Zhangjia, municipio de Lianhua, condado de Yongjing, en la provincia noroccidental de Gansu. Debido a la construcción del embalse de Liujiaxia, el pueblo ya no existe. El joven Zifan y su familia fueron trasladados al municipio de Hetan, en el condado autónomo de Dongxiang, provincia de Gansu. El padre de Zifan era miembro del PCCh y un comunista acérrimo, descrito por los aldeanos como totalmente entregado al Partido, donde ocupó diferentes cargos de liderazgo local. La madre de Zifan acudía a un templo budista y transmitió a su hijo el interés por el budismo. ${ }^{74}$

Zifan fue estudiante en la Escuela Media $\mathrm{N}^{\circ} 3$ del condado de Dongxiang, luego en la Escuela Técnica Geológica de Zhangjiakou del Ministerio de Geología y Recursos Minerales, en el Instituto de Educación de Lanzhou, el Instituto de Educación de Jiuquan y la Universidad de Negocios y Economía Internacional de Pekín. ${ }^{75}$

74 Xuefeng, “为喜好偷窥者提供雪峰的基本情况” [Información básica sobre Xuefeng para los que les gusta espiar], 3 de marzo de 2012. https://chanyuan.org/guide/81272d7cc10f11eab31b560002b98003/66ce132c355a11eba9e5560002b98003

75 Ibíd. 
Como era de esperar del hijo de un burócrata local del PCCh, Zifan se afilió al Partido cuando cumplió 18 años, en 1975. Rápidamente se convirtió en secretario de rama del PCCh en su brigada de producción rural. Enseñó inglés y también trabajó como intérprete para los líderes locales del PCCh y los empresarios. Como tal, fue enviado a África por la Oficina de Geología y Recursos Minerales de Gansu en 1993, y se estableció en Zimbabue en $1995 .^{76}$

Le gustó el país y decidió no volver a China. Obtuvo un permiso de residencia e invirtió sus ahorros en la fundación y desarrollo de una empresa que poseía tiendas, restaurantes y bares en Zimbabue. También exploró las iglesias cristianas locales. Más tarde, Zifan informó que había tenido una experiencia cercana a la muerte tras un accidente de coche en la carretera entre Harare, la capital de Zimbabue, y Mutare, durante la cual "murió" como Zhang Zifan y "renació" como el maestro Xuefeng, el profeta de la nueva era y la encarnación del mismo espíritu divino que antes se había encarnado como Lao Tzi, Buda, Jesús y Mahoma. ${ }^{77}$ Comenzó a escribir libros y a reunir seguidores, y en 2005 fundó el Templo Zen de la Vida en Zimbabue.

Siguió siendo ciudadano chino y miembro del PCCh. En algún momento, abandonó el Partido, pero afirma que "mi creencia de toda la vida en la realización del comunismo no ha cambiado" 78 y Marx y el presidente Mao siguen estando entre sus principales referencias.

A partir de 2009, comenzó a fundar comunidades en China, las cuales en un principio fueron toleradas y en ocasiones incluso apoyadas por las autoridades, que encontraban tranquilizadoras sus referencias al comunismo y al presidente Mao. En esta etapa, se puede decir que el Templo Zen de la Vida ocupaba una posición peculiar en el mercado rojo.

76 Xuefeng. “雪峰的自我介绍和奇异车祸” [Autopresentación de Xuefeng y su extraño accidente de coche]. 2018. https://chanyuan.org/guide/81272d7cc10f11eab31b560002b98003/4e701712350f11eba9e5560002b98003

77 Xuefeng. “雪峰的自我介绍和奇异车祸” [Autopresentación de Xuefeng y su extraño accidente de coche]. 2018.

78 Xuefeng, “为喜好偷窥者提供雪峰的基本情况”, 2012. 
El apoyo y la tolerancia fueron, sin embargo, efímeros. En 2014, un periodista del New York Times visitó la comunidad del Templo Zen de la Vida cerca de Lincang, en la provincia de Yunnan, habló con Xuefeng y publicó un relato sorprendentemente favorable del grupo. ${ }^{79} \mathrm{El}$ artículo del Times también señalaba que otras comunidades del Templo Zen de la Vida se habían visto obligadas a cerrar y que la propia comuna de Yunnan estaba sometida a un fuerte acoso por parte de la Seguridad Pública local. ${ }^{80} \mathrm{El}$ Templo había pasado del mercado rojo al mercado gris. Que esto ocurriera después de que Xi Jinping llegara al poder no fue una coincidencia.

El Times describió la comuna como "un experimento comunista” y una "comunidad rural utópica" que recordaba en cierto modo a la Revolución Cultural, con miembros que trabajaban duro en el campo y vivían de los frutos de su propia agricultura y avicultura. ${ }^{81}$ Pero era más que eso. Aunque Xuefeng insiste en que el Templo Zen de la Vida no es una religión y no tiene rituales, se supone que los creyentes reconocen que el fundador es una encarnación divina y los guiará hacia el Milenio. A cada creyente se le llama "hierba del jardín Zen" y se le pide que añada la palabra "hierba" a su nombre.

El Templo cree que en 2018 comenzó un período de 30 años de tribulaciones. Cómo será este "frío invierno", y si implicará desastres apocalípticos, depende de la actitud de la humanidad y del propio Templo. Lo que sucederá después se presenta como hipotético, pero es posible que el Planeta Tierra se fusione con el Milenio, que ya existe como un planeta situado a 960 años luz de la Tierra. Es diez veces más grande que el Planeta Tierra, y las almas de los difuntos que se han salvado van allí en unos dieciséis minutos. El Templo niega que (como sostienen sus opositores) sólo se salven sus miembros. De hecho, otras personas que lleven una vida

79 Dan Levin, “云南生命禅院的共产主义实验” [El experimento comunista en el Templo Budista de la Vida de Yunnan], The New York Times (ed. china), 14 de marzo de 2014. https://cn.nytimes.com/china/20140314/c14lincang/ 80 Ibíd.

81 Ibíd. 
buena y desinteresada también entrarán en el Milenio, que sin embargo no acogerá a más del $1 \%$ de la población actual de la Tierra. ${ }^{82}$

El Milenio es también donde se realiza la perfecta "sociedad sin clases" profetizada por Marx, Lenin y el presidente Mao. En la Tierra, sin embargo, la misión del Templo es establecer pequeñas réplicas del Planeta Milenio en forma de comunas que deben ser "paraísos para las clases trabajadoras", y donde se realiza el "comunismo al estilo Xuefeng". "El comunismo es el único camino hacia la felicidad para las masas trabajadoras, y es también la única salida para la humanidad", ${ }^{83}$ enseña Xuefeng. El "comunismo al estilo Xuefeng" es, sin embargo, diferente del "comunismo histórico" tal y como existe en la China actual. El comunismo del Templo incluye un elemento espiritual, un camino hacia la inmortalidad en el Milenio y hacia la "budeidad" y la iluminación en la Tierra. También critica al PCCh por "haber puesto el pensamiento de Mao en las estanterías" y haber reintroducido elementos del capitalismo. ${ }^{84}$

Una característica importante del "comunismo al estilo Xuefeng", que el Templo cree que forma parte de la verdadera esencia del comunismo de Marx, es la eliminación de la familia burguesa, sustituida por el amor libre y la educación comunitaria de los niños. ${ }^{85}$ Según Xuefeng, "la familia es la principal fuente de sufrimiento en la vida. Si la familia no se disuelve,

82 Life Zen Temple.. “新时代人类八百理念” [Ochocientas ideas para la humanidad en la nueva era]. 2017.

83 Xuefeng, “共产主义--劳苦大众的唯一幸福之路” [El comunismo: el único camino hacia la felicidad de los trabajadores], 20 de noviembre de 2020. https://chanyuan.org/guide/dc09cb64c0f111eab31b560002b98003/b35883e23f4811eba9e5560002b98003

84 Ibid.

85 Xuefeng, “传统家庭和禅院 “家庭 “的区别” [La diferencia entre la familia tradicional y la 'familia' del Templo]. 20 de septiembre de 2007. https://chanyuan.org/guide/3b7e6558f8c111eab64b560002b98003/d0da70cc355411eba9e5560002b98003 
la humanidad no podrá entrar en una nueva era llena de libertad y felicidad" ${ }^{86}$ En el Milenio en la Tierra (pero ya en las comunas del Templo),

la familia desaparecerá, la ceremonia matrimonial dejará de existir, el certificado de matrimonio se convertirá en una reliquia histórica, el título de esposa y esposo se convertirá en un signo de ignorancia y atraso, y quedará confinado a los museos de historia. El amor entre hombres y mujeres se realizará a voluntad siempre que sea consentido. ${ }^{87}$

Esto no significa que la sexualidad sea vista con recelo por el Templo. De hecho, se celebra ${ }^{88}$ y la Seguridad Pública difundió imágenes de representaciones teatrales en las comunas de Guizhou que, a su juicio, demuestran la "inmoralidad" del grupo.

El comunismo maoísta puro ya es sospechoso en la China actual, ya que implica una crítica a los líderes del Partido posteriores a Mao, incluido $\mathrm{Xi}$ Jinping, pero el amor libre promovido a través del milenarismo religioso ciertamente no se tolera. En 2017, también en previsión de los próximos 30 años de problemas, Xuefeng se trasladó a Canadá, donde tiene seguidores (existen otros grupos del Templo Zen de la Vida en Tailandia), y ordenó a las comunidades en China que pasaran a la clandestinidad.

Esto ya era una señal de que el grupo, habiendo pasado del mercado rojo al gris, estaba cayendo lenta pero seguramente en el mercado negro. Esto se oficializó con la redada de 2021.

\section{Conclusión}

Algunos pueden argumentar que los grupos comunales que experimentan con alternativas a la familia tradicional tampoco fueron nunca

86 Ibíd.

87 “Chaos Grass”, “家庭将逐渐消失: 论生命禅院时代五” [Las familias desaparecerán gradualmente. Sobre la quinta era del Templo de la Vida Budista], 2006. https://chanyuan.org/guide/7ec27dc40e8311e9be60befb453e417e/ b062b84c198911e9aee5befb453e417e

88 Véase por ejemplo, “Wisdom Grass”, “性的真相和极致” [La verdad y el extremo del sexo], 2018. https://chanyuan.org/guide/3b7e6558f8c111eab64b560002b98003/1b67360a7fb411e9aee5befb453e417e 
populares en Occidente, y los problemas con los que se encontraron los Niños de Dios, posteriormente rebautizados como La Familia, ofrecen un claro ejemplo de cómo tales movimientos son fácilmente tachados de "sectas inmorales" y perseguidos. ${ }^{89}$

Es cierto que el movimiento antisectas está a su vez globalizado y es transnacional, y que China ha importado rasgos del movimiento antisectas de Occidente. Sin embargo, lo interesante del Templo Zen de la Vida es que era un movimiento religioso comunista, en el que el amor libre se promovía en nombre del comunismo y no de la religión. Dado que existe una tradición de amor libre dentro del marxismo desde sus inicios, y que tanto Karl Marx (1818-1883) como, más enfáticamente, Friedrich Engels (1820-1895) anticiparon que la familia desaparecería en una sociedad comunista plenamente realizada, ${ }^{90}$ el maestro Xuefeng, a diferencia de los líderes de los Niños de Dios en Occidente, podía afirmar que simplemente estaba reconectando con los orígenes de la ideología oficial de la sociedad en la que vivía.

$\mathrm{Al}$ igual que los grupos parapsicológicos anti-Einstein, con sus relatos de energías ocultas, fueron aceptados en su día porque decían defender la ciencia marxista frente a la ciencia burguesa occidental, durante un tiempo el movimiento de Xuefeng tuvo el sabor de un comunismo romántico y gozó de cierta simpatía y tolerancia.

Sin embargo, con la llegada de Xi Jinping, se eliminaron todos los "flecos” de la ideología, la filosofía y la religión. El único marxismo aceptado fue el de Xi Jinping, y las únicas religiones aceptadas fueron las que el PCCh declaró aceptables. La parábola del Templo Zen de la Vida es sólo una nota a pie de página dentro del texto más amplio de cómo Xi Jinping reprimió, de diferentes maneras, todas las formas de religión. Pero es, a su manera, una confirmación de que incluso los focos de independencia

89 James R. Lewis y J. Gordon Melton, Sex, Slander, and Salvation: Investigating The Family / Children of God (Stanford, CA: Center for Academic Publication, 1994).

90 Richard Weikart, "Marx, Engels, and the Abolition of Family", History of European Ideas 18, no. ${ }^{\circ} 5$ (1994.):657-72. 
menores y clandestinos son identificados y destruidos en nombre de la "armonía social" de Xi Jinping, que se percibe como el valor central de una sociedad en la que se promueven la seguridad pública y la estabilidad a costa de la tolerancia religiosa e ideológica.

\section{Referencias}

Beadle, John Hanson. “The Mormon Theocracy”. Scribner's Monthly. 14. n. 3 (1877): 391-97.

“Chaos Grass”. “家庭将逐渐消失：论生命禅院时代五” [Las familias desaparecerángradualmente.SobrelaquintaeradelTemplodelaVidaBudista]. 2006. https://chanyuan.org/guide/7ec27dc40e8311e9be60befb453e417e/ b062b84c198911e9aee5befb453e417e

Chau, Adam Yuet. Religion in China: Ties That Bind. Oxford, UK y Medford, MA: Polity Press. 2019.

Chen, Qingping. "Reflection on the Definition of Cults and Its Related Problems". Ponencia presentada en la conferencia The Question of Xiejiao in China and the Case of the Church of Almighty God. Universidad de Hong Kong, 15 y 16 de septiembre de 2017.

Chen, Wangli. "China Moves Against the Christian Darakbang Movement”. Bitter Winter, 16 de junio de 2021a. https:// bitterwinter.org/china-moves-against-the-christian-darakbangmovement/

Chen, Wangli. "Manmin Central Church Believers Detained in Different Provinces”. Bitter Winter. 11 de julio de 2021b. https://bitterwinter. org/ccp-cracks-down-on-korea-based-good-news-mission/

Chen, Wangli. "Manmin Central Church Believers Detained in Different Provinces”. Bitter Winter. 22 de junio de 2021c. https:// bitterwinter.org/manmin-central-church-believers-detained-indifferent-provinces/

Comité Central del Partido Comunista Chino. "Document 19: The Basic Viewpoint on the Religious Question during Our Country's Socialist Period". 1982. https://www.globaleast.org/wp-content/ uploads/2020/02/Document_no._19_1982.pdf 
Consejo de Estado de China. "Religious Affairs Regulation 2017". Traducción al inglés por China Law Translate. 2017. https://www. chinalawtranslate.com/en/religious-affairs-regulations-2017/

Farrelly, Paul. "Spiritual Revolutions: A History of New Age Religion in Taiwan". Tesis de Doctorado. Universidad Nacional de Australia, Canberra, 2017.

Feng, Gang. "Cómo las autoridades desmantelaron la Iglesia de Zion emplazada en Pekín”. Bitter Winter, 16 de septiembre de 2018. https://es.bitterwinter.org/autoridades-desmantelaron-la-iglesia-dezion/

Goossaert, Vincent y David A. Palmer. The Religious Question in Modern China. Chicago: University of Chicago Press, 2011.

Greil, Arthur L. 'Sacred Claims: The 'Cult Controversy' as a Struggle over the Right to the Religious Label”. En The Issue of Authenticity in the Study of Religion, editado por David G. Bromley y Lewis F. Carter, 47-63. Greenwich, CT: JAI Press, 1996.

Introvigne, Massimo. [de próxima publicación]. Brainwashing: Reality or Myth?. Cambridge, Reino Unido: Cambridge University Press, 2022.

Introvigne, Massimo. Inside The Church of Almighty God: The Most Persecuted Religious Movement in China. New York: Oxford University Press, 2020.

Introvigne, Massimo, James T. Richardson y Rosita Šorytė. "Prophecy, Passports, and Persecution: Church of Almighty God Asylum Cases, 2015-2021". The Journal of CESNUR 5, no 3 (2021): 3-135.

Introvigne, Massimo, James T. Richardson y Rosita Šorytė. "Would the Real Article 300 Please Stand Up? Refugees from Religious Movements Persecuted as Xie Jiao in China: The Case of The Church of Almighty God”. The Journal of CESNUR 3, no 5 (2019): 3-86.

Irons, Edward. "Importantes cambios en las estructuras encargadas de combatir a los xie jiao en China". Bitter Winter, 25 de febrero de 2019. https://es.bitterwinter.org/cambios-en-las-estructurasencargadas-de-combatir-a-los-xie-jiao/ 
Irons, Edward. "The List: The Evolution of China's List of Illegal and Evil Cults". The Journal of CESNUR 2, no. ${ }^{\circ} 1$ (2018): 33-57.

Levin, Dan. “云南生命禅院的共产主义实验” (El experimento comunista en el Templo Budista de la Vida de Yunnan). The New York Times (ed. China), 14 de marzo de 2014. https://cn.nytimes. com/china/20140314/c14lincang/

Lewis, James R. y J. Gordon Melton. Sex, Slander, and Salvation: Investigating The Family / Children of God. Stanford, CA: Center for Academic Publication, 1994.

Li, Jianglin. Tibet in Agony: Lhasa 1959. Cambridge, MA: Harvard University Press, 2016.

Life Zen Temple. “新时代人类八百理念” [Ochocientas ideas para la humanidad en la nueva era], 2017. https://chanyuan.org/\#c-valuessheet1-tab1

Liu, Mengyao. "Anti-Einstein Relativity Research Association Banned As a 'Cult”. Bitter Winter, 13 de julio de 2021. https://bitterwinter. org/anti-einstein-relativity-research-association-banned-as-a-cult/

Madsen, Richard. China's Catholics: Tragedy and Hope in an Emerging Civil Society. Berkeley: University of California Press, 1998.

Melton, J. Gordon. "Xiejiao, Cults, and New Religions: Making Sense of the New Un-Sinicized Religions on China's Fringe”. Ponencia presentada en la conferencia Sinicization of Religion in China: From Above and Below. University of California, San Diego, marzo de 2018.

Meng, Yuanxin. "The New Socialism Reform or Delusion to Eradicate Religion: An Analysis of the New Religious Affairs Regulations and the Chinese Communist Party's Religious Policy during the Xi Administration”. Chinese Law and Religion Monitor 11, no. ${ }^{\circ} 1$ (2018): 21-64.

Ownby, David. Falun Gong and the Future of China. New York: Oxford University Press, 2008.

Palmer, David Alexander. Qigong Fever: Body, Science, and Utopia in China. New York: Columbia University Press, 2007. 
Palmer, David Alexander. "Heretical Doctrines, Reactionary Secret Societies, Evil Cults: Labelling Heterodoxy in 20th-Century China". En Chinese Religiosities: The Vicissitudes of Modernity and State Formation, editado por Mayfair Yang, 113-34. Berkeley CA: University of California Press, 2012.

Santa Sede "Orientaciones pastorales sobre el registro civil del clero en China”. Press.Vatican, 28 de junio de 2019. https://press.vatican.va/ content/salastampa/es/bollettino/pubblico/2019/06/28/tex.html

Shao, Yong. 中國會道門 [Sectas y sociedades secretas chinas]. Shanghái: Shanghai renmin chubanshe, 1997.

Šryte, Rosita. 'Labeling Scientology: 'Cult,' 'Fringe,' 'Extremist,' or Mainstream?”. The Journal of CESNUR 5, no. ${ }^{\circ}$ (2021): 58-76.

Stark, Rodney y Wang Xiuhua. A Star in the East: The Rise of Christianity in China. West Conshohocken, PA: Templeton Press, 2015.

Vala, Carsten T. The Politics of Protestant Churches and the Party-State in China: God above Party? London: Routledge, 2018.

Walsh, Michael. Stating the Sacred: Religion, China, and the Formation of the Nation-State. New York: Columbia University Press, 2020.

Weikart, Richard. "Marx, Engels, and the Abolition of Family". History of European Ideas 18, no. ${ }^{\circ} 5$ (1994.):657-72.

“Wisdom Grass”. “性的真相和极致” [La verdad y el extremo del sexo]. 2018. https://chanyuan.org/

Wu, Junqing. Mandarins and Heretics: The Constructions of "Heresy" in Chinese State Discourse. Leiden: Brill, 2017.

Wu, Junqing. "Words and Concepts in Chinese Religious Denunciation: A Study of the Genealogy of Xiejiao". The Chinese Historical Review 23, no. ${ }^{\circ} 1(2016): 1-22$.

Xinhua. "Xi Calls for Improved Religious Work", 24 de abril de 2016. http://www.china.org.cn/china/2016-04/24/content_38312410. htm

$\mathrm{Xu}$, Tao. "The Comparison and Dialogue of Definitions of Cult between China and America". Ponencia presentada en la conferencia The Question of Xiejiao in China and the Case of the Church of Almighty God. Universidad de Hong Kong, 15 y 16 de septiembre 2017. 
Xuefeng. “共产主义--劳苦大众的唯一幸福之路” [El comunismo: el único camino hacia la felicidad de los trabajadores]. 20 de noviembre de 2020. https://cutt.ly/cUYuxXJ

Xuefeng. “雪峰的自我介绍和奇异车祸” [Autopresentación de Xuefeng y su extraño accidente de coche]. 2018. https://cutt.ly/BUYusw7

Xuefeng. “为喜好偷窥者提供雪峰的基本情况” [Información básica sobre Xuefeng para los que les gusta espiar]. 3 de marzo de 2012. https:// cutt.ly/rUYuYPq

Xuefeng. “传统家庭和禅院“家庭“的区别” [ La diferencia entre la familia tradicional y la 'familia' del Templo]. 20 de septiembre de 2007. https://chanyuan.org/guide/3b7e6558f8c111eab64b560002b98003/ d0da70cc355411eba9e5560002b98003

Yang, Feng. "The Great Purge of China Legal History". Bitter Winter, 28 de junio de 2021. https://bitterwinter.org/the-great-purge-of-china-legalhistory/

Yang, Fenggang. Religion in China: Survival and Revival Under Communist Rule. New York: Oxford University Press, 2012.

Yang, Fenggang. "The Red, Black, and Gray Markets of Religion in China". Sociological Quarterly 47, no. ${ }^{\circ}$ (2006): 93-122.

Yang, Fenggang. "Between Secularist Ideology and Desecularizing Reality: The Birth and Growth of Religious Research in Communist China". Sociology of Religion 65, no.22 (2004):101-19.

Yao, Zhangjin. "El Partido Comunista Chino fabrica evidencia para acusar al pastor Wang Yi”. Bitter Winter, 25 de junio de 2019. https:// es.bitterwinter.org/el-pcch-fabrico-evidencia-para-acusar-al-pastorwang-yi/

Zhang, Chunhua. "Christian Churches Ordered to Preach Xi Jinping's July 1 Speech”. Bitter Winter, 14 de julio de 2021. https://bitterwinter.org/ christian-churches-ordered-to-preach-xi-jinpings-july-1-speech/

Zhang, Xinzhang. "The Potential Illegitimacy of the PRC's Effort to Distinguish Xie Jiao from 'Cult' or 'Destructive Cult'. Alternative Spirituality and Religion Review 11, no. ${ }^{\circ} 1$ (2020): 81-95. 